\title{
A New Method for Fabrication of Nanohydroxyapatite and TCP from the Sea Snail Cerithium vulgatum
}

\author{
O. Gunduz, ${ }^{1,2}$ Y. M. Sahin, ${ }^{3}$ S. Agathopoulos, ${ }^{4}$ B. Ben-Nissan, ${ }^{5}$ and F. N. Oktar ${ }^{2,6,7}$ \\ ${ }^{1}$ Department of Metal Education, Faculty of Technical Education, Marmara University, Kadiköy, 34722 Istanbul, Turkey \\ ${ }^{2}$ Center for Nanotechnology and Biomaterials Applied \& Research, Marmara University, Kadıköy, 34722 Istanbul, Turkey \\ ${ }^{3}$ Department of Biomedical Engineering, Faculty of Engineering and Architecture, Istanbul Arel University, Buyukcekmece, \\ 34537 Istanbul, Turkey \\ ${ }^{4}$ Department of Materials Science and Engineering, University of Ioannina, P.O. Box 1186, 45110 Ioannina, Greece \\ ${ }^{5}$ Department of Chemistry and Forensic Science, University of Technology Sydney, P.O. Box 123, Broadway, Ultimo, Sydney, \\ NSW 2007, Australia \\ ${ }^{6}$ Department of Bioengineering, Faculty of Engineering, Marmara University, Kadiköy, 34722 Istanbul, Turkey \\ ${ }^{7}$ Department of Medical Imaging Techniques, School of Health Related Professions, Marmara University, Tibbiye Street No. 49, \\ Üsküdar, 34688 Istanbul, Turkey \\ Correspondence should be addressed to O. Gunduz; oguzhan@marmara.edu.tr and F. N. Oktar; foktar@marmara.edu.tr
}

Received 26 July 2013; Accepted 27 November 2013; Published 2 January 2014

Academic Editor: Il-Kwon Oh

Copyright (C) 2014 O. Gunduz et al. This is an open access article distributed under the Creative Commons Attribution License, which permits unrestricted use, distribution, and reproduction in any medium, provided the original work is properly cited.

\begin{abstract}
Biphasic bioceramic nanopowders of hydroxyapatite (HA) and $\beta$-tricalcium phosphate (TCP) were prepared from shells of the sea snail Cerithium vulgatum (Bruguière, 1792) using a novel chemical method. Calcination of the powders produced was carried out at varying temperatures, specifically at $400^{\circ} \mathrm{C}$ and $800^{\circ} \mathrm{C}$, in air for 4 hours. When compared to the conventional hydrothermal transformation method, this chemical method is very simple, economic, due to the fact that it needs inexpensive and safe equipment, because the transformation of the aragonite and calcite of the shells into the calcium phosphate phases takes place at $80^{\circ} \mathrm{C}$ under the atmospheric pressure. The powders produced were determined using infrared spectroscopy (FT-IR), X-ray diffraction, and scanning electron microscopy (SEM). The features of the powders produced along with the fact of their biological origin qualify these powders for further consideration and experimentation to fabricate nanoceramic biomaterials.
\end{abstract}

\section{Introduction}

To date, biomaterials is a rapidly developing interdisciplinary field at the interface of engineering, science, and healthcare industry; its effect on human health related issues is also obvious and recognized all over the world. The global biomaterials device market was estimated as $\$ 115.4$ billion in 2008 and is expected to increase to $\$ 252.7$ billion in 2014. The largest market share among all biomaterial products belongs to orthopedic biomaterials [1], like hydroxyapatite (HA) materials. With a chemical formula of $\mathrm{Ca}_{10}\left(\mathrm{PO}_{4}\right)_{6}(\mathrm{OH})_{2}$, $\mathrm{HA}$ is the main inorganic component of bone [2] and tooth [3]. Thus, HA is very popular for implant materials especially in orthopedic bone surgery [2] and other hard tissue implantations [3], such as in dental and aesthetic surgery.

Powders of HA can be produced with very various chemical techniques, such as precipitation, hydrothermal techniques, hydrolysis of other calcium phosphates, and solgel [4] from very pure chemicals or from natural materials. Calcination is another method to fabricate HA from different natural sources, like bone (i.e., human [5], bovine [6], sheep [7], turkey, and chicken) or tooth dentine [8] and enamel [911]. In previous work, there are also papers reporting some very interesting sources for HA production, such as crocodile bone [12], dear antler [13], and fish wastes. 


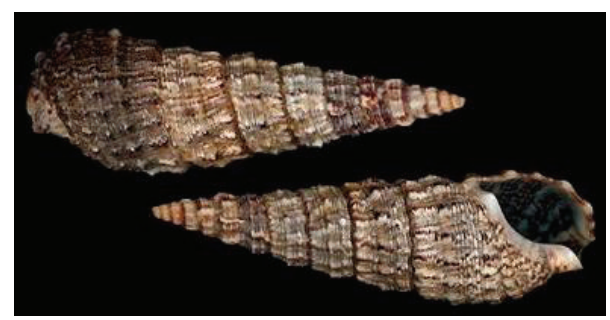

FIgURE 1: Typical photos of shells of Cerithium vulgatum Bruguière, 1792, Mediterranean [30].

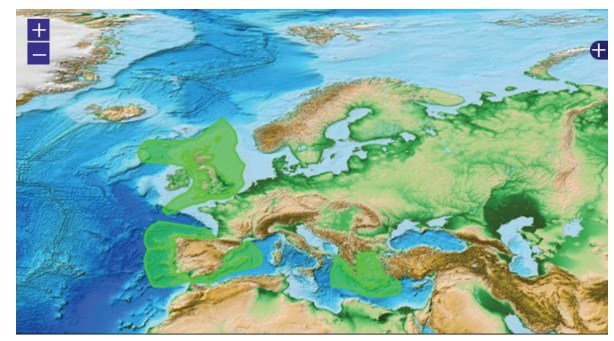

FIGURE 2: Habitation areas for Cerithium vulgatum [31].

Hydrothermal methods are very popular to transform various sources with a sea origin, such as cuttlefish bone [14], some oysters [15], and corals [16]. In our more recent studies, we have presented some very simple mechanochemical methods, which can be conducted with a simple hot-plate stirrer and with ultrasonic equipment $[17,18]$. Various aragonitic structures, such as cuttlefish bone [19], sea [20] and land snail shells [21], sea urchin shells [17, 18, 20], various mussel shells [19, 22-24], pearl powder [25], corals [16], and calcite from egg shells [26], were successfully transformed into various $\mathrm{Ca}$-phosphate bioceramic powders using these novel mechanochemical methods.

In this work, a novel and simple chemical method was utilised to fabricate nanobiphasic powders of HA and TCP from the shells of a local sea snail, Cerithium vulgatum Bruguière, 1792 [27]. The Cerithium vulgatum is a species of sea snail, which is a marine gastropod mollusk and also belongs to the family Cerithiidae [28]. Generally the Cerithium vulgatum shells are occupied by hermit crabs [29]. The typical shape of these shells is revealed in Figure 1 [30].

\section{Materials and Experimental Procedure}

Generally, the habitation areas for Cerithium vulgatum are all coastal areas of the United Kingdom, Spain, Portugal, Greece, and West of Turkey (Figure 2, [31]). These species can be obtained from the Black Sea in Turkey [32]. Thus, it is not surprising to come across with the empty shells of the sea snail Cerithium vulgatum Brugui'ere by the Marmara Sea, in Turkey, and specifically by the beaches of Princes Islands. However, the collection of the Cerithium vulgatum shells is generally difficult by the beaches of Istanbul since their number are quite small and are negligible in comparison to those of other collected shells. The other shells mainly belong to the species Nassarius hinnia reticulatus (this species is overnumbered in these beaches). However, the shells of Cerithium vulgatum are easily recognized and separated from the shells of Nassarius hinnia reticulatus because the latter ones are much smaller in length and diameter than the former ones and have a brownish color.

Empty shells of a local sea snail (Cerithium vulgatum Bruguière, 1792) were taken from a local beach in Princes Islands, Heybeli Island (local beach name; German Beach) in Istanbul, Turkey. No living creatures were used in this study at all. The empty shells were cleaned thoroughly from sand particles and other foreign materials. Then, the shells were dried and crushed into small particles and finally planetarymilled in a porcelain jar. The milled powder was sieved using a $100 \mu \mathrm{m}$ sieve (i.e., the particle size was $<100 \mu \mathrm{m}$ ).

A small sample of the fine powder was analyzed using differential thermal and gravimetric analysis (DTA/TGA) to determine the exact $\mathrm{CaCO}_{3}$ content. Batches of $2 \mathrm{~g}$ of powder were suspended in an aqueous solution of distilled water in a conical flask. Then, according to a previous study [33], solution of $\mathrm{H}_{3} \mathrm{PO}_{4}$ was added in such an amount as to satisfy the stoichiometric molar ratio of $\mathrm{Ca} / \mathrm{P}$ equal to 1.667 (that corresponds to HA; this sample is hereafter designated as A) or 1.5 (that corresponds to TCP; this sample is hereafter designated as B). Hot-plate stirrer equipment was used with a conical flask in this work. The temperature of the solution was set at $80^{\circ} \mathrm{C}$ and the reaction took place for $8 \mathrm{~h}$ under continuous stirring. After that, the powders were removed from the liquid by filtration and dried at $100^{\circ} \mathrm{C}$ overnight in an incubator. The dried powders were calcined using an electric furnace (Nabertherm HT 16/17, Lilienthal, Germany) for $4 \mathrm{~h}$ in air. The powders of the sample $\mathrm{A}$ (i.e., $\mathrm{Ca} / \mathrm{P}=1.667$ ) and the powders of the sample $\mathrm{B}$ (i.e., $\mathrm{Ca} / \mathrm{P}=1.5$ ) were calcined at $800^{\circ} \mathrm{C}$ and $400^{\circ} \mathrm{C}$, respectively.

To characterize the materials, in either the raw form or the final powders, the following equipment was used. The thermal analysis was determined using DSC-DTA-TG equipment (TA SDT Q600 Protherm). The observation of the microstructure of the samples was observed in a scanning electron microscope (SEM, JEOL JSM 7000F Field Emission Scanning Electron Microscope, equipped with a Hitachi 1000 Tabletop microscope). The crystalline phases developed in the calcined powders were used by X-ray diffraction analysis (Bruker D8 Advance X-ray diffractometer). The Fourier transform infrared (FT-IR) spectra of the produced powders were analyzed in a Bruker ALPHA FT-IR spectrometer.

\section{Results and Discussion}

The typical microstructure at a fracture surface of the shells is revealed in the low-magnification SEM image of Figure 3. A plate-like structure can be attributed largely to aragonite crystals. The direction of the plates is perpendicular to the outer (upper part in the image) and the inner surfaces of the shell. The outer surface apparently has a less dense structure. Calcite is expected to be concentrated in the outer layer of the shell. The inner layer (lower part in the image) has apparently a denser structure. Usually, the inner part of the 


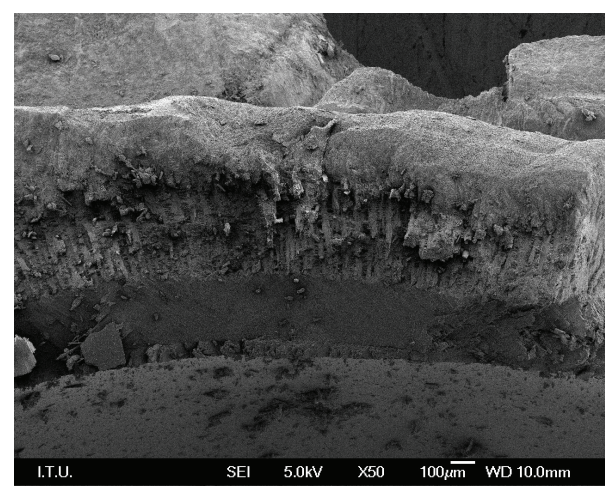

Figure 3: Microstructure at fracture surface of Cerithium vulgatum shell.

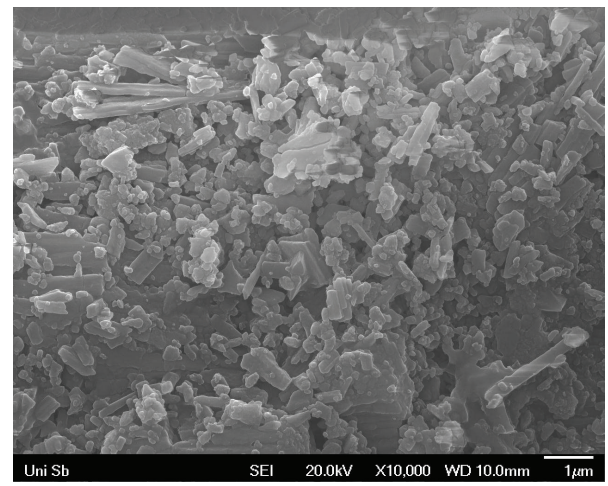

FIGURE 4: SEM image of raw powder after planetary milling and sieving with a sieve of $100 \mu \mathrm{m}$.

shells is largely made of aragonite. Therefore, the raw powder that was subjected afterwards to transformation into calcium phosphates should involve both the phases of aragonite and calcite, which is observed in all regular shells. But the influence of aragonite-calcite sea conditions on the evolution of biocalcification remained up to now poorly understood [34].

The nanopowders were spontaneously fabricated after crushing, milling, and sieving, as shown in the SEM image of Figure 4 . The powder mainly consisted of prismatic particles with a semirounded shape and nanosize dimensions of about $200 \mathrm{~nm}$. Some elongated rod-like prismatic particles with a length of ca $1-1.5 \mu \mathrm{m}$ and a width of ca $200 \mathrm{~nm}$ are also observed.

The results of the differential and gravimetric thermal analysis (DTA/TGA) of the raw powders after milling and sieving are plotted in the diagrams of Figure 5 . The decomposition of $\mathrm{CaCO}_{3}$ to $\mathrm{CaO}$ was clearly obtained in both curves. These curves confirm that the shell was exclusively consisted of $\mathrm{CaCO}_{3}$. Thus, the calculation of the amount of $\mathrm{H}_{3} \mathrm{PO}_{3}$ solution required to satisfy the demanded $\mathrm{Ca} / \mathrm{P}$ ratios was possible.

The X-ray analysis of the powders produced after calcination for $4 \mathrm{~h}$ in air is shown in the diffractograms of Figure $6(\mathrm{a})$, for the powder $\mathrm{B}\left(\mathrm{Ca} / \mathrm{P}=1.5,400^{\circ} \mathrm{C}\right)$, and Figure $6(\mathrm{~b})$, for the powder $\mathrm{A}\left(\mathrm{Ca} / \mathrm{P}=1.667,800^{\circ} \mathrm{C}\right)$. From

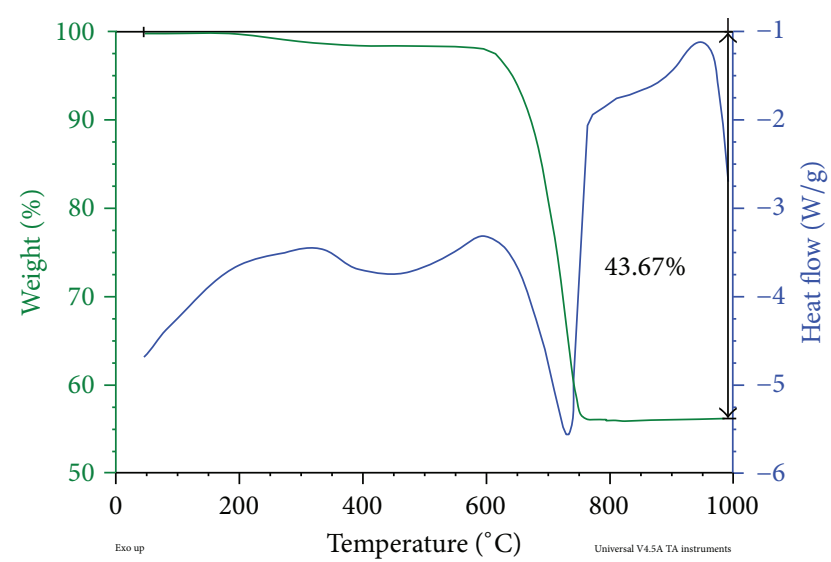

FIGURE 5: Differential and gravimetric thermal analysis (DTA/TGA) of the raw powders (after planetary milling and sieving).

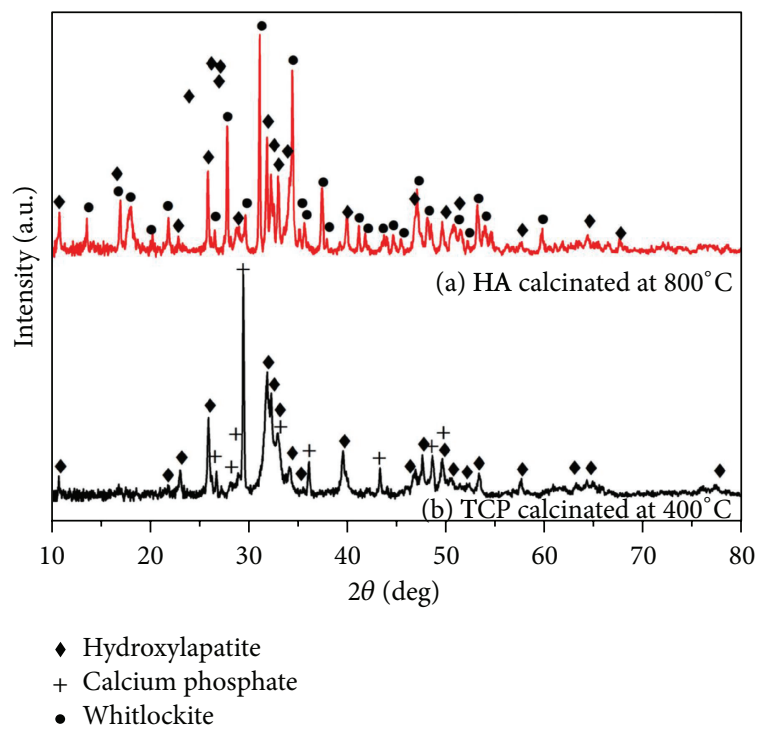

Figure 6: X-ray diffractograms of the produced powders after calcination for $4 \mathrm{~h}$ in air: (a) powder $\mathrm{B}\left(\mathrm{Ca} / \mathrm{P}=1.5,400^{\circ} \mathrm{C}\right)$; (b) powder $\mathrm{A}\left(\mathrm{Ca} / \mathrm{P}=1.667,800^{\circ} \mathrm{C}\right)$.

these diffractograms it is concluded that the transformation of $\mathrm{CaCO}_{3}$, in the form of either aragonite or calcite, was completely indicated. In both diffractograms, the phase of HA was clearly observed (JCPDS card 00-009-0432 in sample $\mathrm{B}$ and JCPDS card 01-089-4405 in sample A; the differences between the two cards are negligible). The second major phase recorded was TCP $\left(3 \mathrm{CaO} \cdot \mathrm{P}_{2} \mathrm{O}_{5}\right)$ in particular $\beta$-TCP in the sample B (JCPDS card 00-009-0346) and whitlockite (JCPDS card 00-009-0169) in the sample A. Whitlockite is also known as $\beta$-tricalcium phosphate ( $\beta$-TCP) [35], which is used in treatment of defects of cortical and cancellous bone due to its osteoconductivity and bioresorbability [36].

The findings of the X-ray analysis indicate that the powders produced are biphasic materials, which comprise HA and TCP. It is well know that the best bioceramic materials 


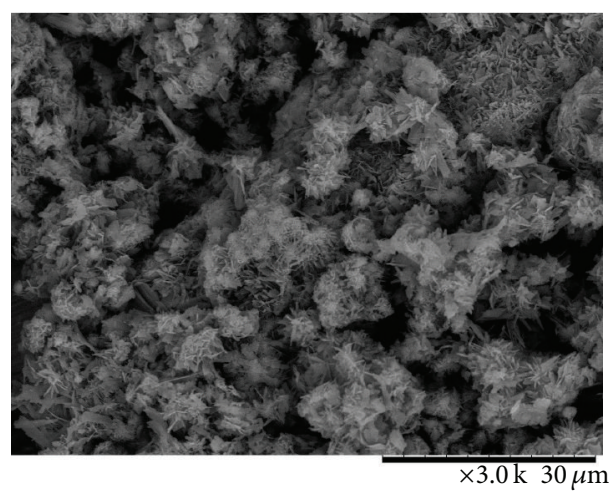

(a)

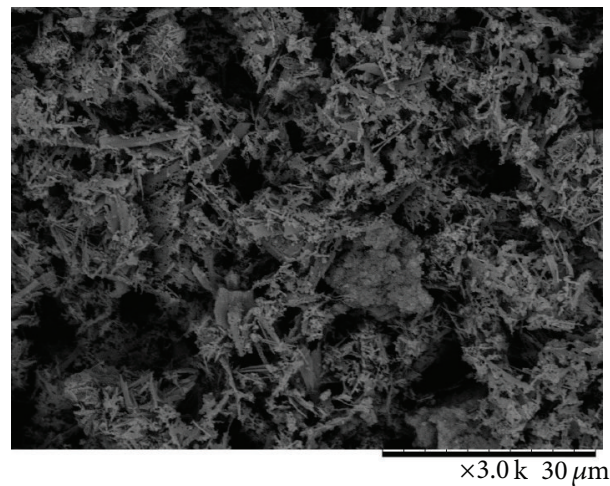

(b)

Figure 7: Microstructure of the produced powders after calcination for $4 \mathrm{~h}$ in air: (a) powder $\mathrm{B}\left(\mathrm{Ca} / \mathrm{P}=1.5,400^{\circ} \mathrm{C}\right)$; (b) powder $\mathrm{A}(\mathrm{Ca} / \mathrm{P}$ $=1.667,800^{\circ} \mathrm{C}$ ).

should ideally consist of biphasic materials of HA and $\beta$ TCP. In such biphasic biomaterials, $\beta$-TCP is the resorbable and osteoconductive [37] component. Usually, resorbable bioceramics are considered as very active and thus they stimulate a faster formation of the newly formed bone. On the other hand, HA presents an excellent biocompatibility and bioactivity.

All the results indicate that the produced powders are very promising materials. However, these good prospects, due to the biphasic crystalline regime of the produced powders, are further enforced because the SEM analysis showed that this production process resulted in the production of nanopowders as well. The characteristic microstructure of the powders produced after calcination for $4 \mathrm{~h}$ in air is shown in the SEM images of Figure $7(\mathrm{a})$, for the powder $\mathrm{B}(\mathrm{Ca} / \mathrm{P}=$ $\left.1.5,400^{\circ} \mathrm{C}\right)$, and Figure $7(\mathrm{~b})$, for the powder $\mathrm{A}(\mathrm{Ca} / \mathrm{P}=1.667$, $800^{\circ} \mathrm{C}$ ). The powder $\mathrm{B}$ comprises prismatic nanoparticles as well as needle-like nanorods with length of $1.5-3 \mu \mathrm{m}$ and diameter of $200 \mathrm{~nm}$. The SEM image of Figure 7(b) for the sample A indicates that this powder is apparently finer than the powder B because there are less prismatic particles; the rod-like (needle-shaped) particles are thinner (with a diameter of ca $150 \mathrm{~nm}$ ), and formation of apparently loosened agglomerations of nanoparticles was also observed, as revealed in the middle of Figure 7(b).

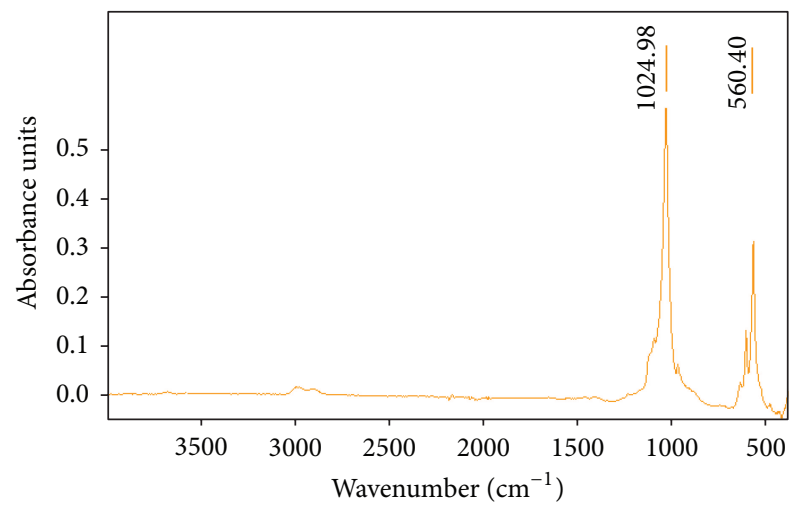

(a)

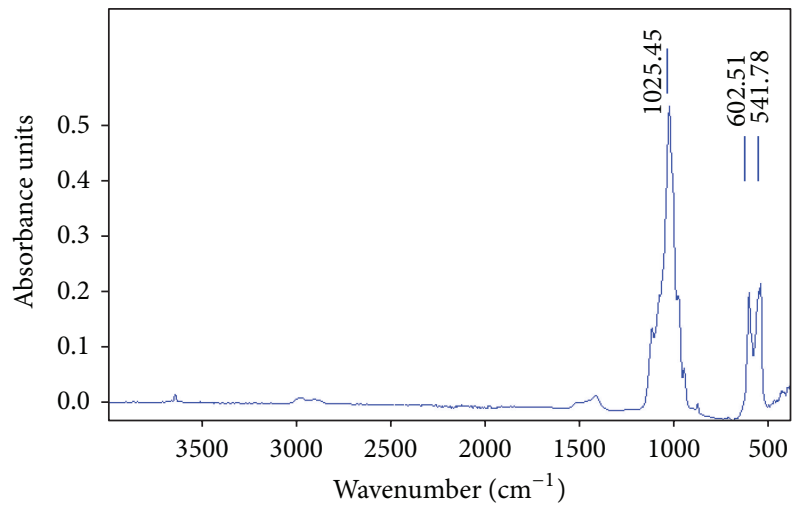

(b)

FIGURE 8: FT-IR spectra of the produced powders after calcination for $4 \mathrm{~h}$ in air: (a) powder $\mathrm{B}\left(\mathrm{Ca} / \mathrm{P}=1.5,400^{\circ} \mathrm{C}\right)$; (b) powder $\mathrm{A}(\mathrm{Ca} / \mathrm{P}$ $=1.667,800^{\circ} \mathrm{C}$ )

FT-IR spectra of the HA powders in the range 4000$400 \mathrm{~cm}^{-1}$ are revealed in Figure 8 for powder $\mathrm{B}(\mathrm{Ca} / \mathrm{P}=$ $1.5,400^{\circ} \mathrm{C}$, Figure $\left.8(\mathrm{a})\right)$ and powder $\mathrm{A}\left(\mathrm{Ca} / \mathrm{P}=1.667,800^{\circ} \mathrm{C}\right.$, Figure 8(b)), after calcination for $4 \mathrm{~h}$ in air. They revealed strong vibrations modes at the following wave numbers: 541, $560,602,1024$, and $1025 \mathrm{~cm}^{-1}$. Absorption bands characteristic of O-P-O bending vibrations can be clearly seen at 541 and $602 \mathrm{~cm}^{-1}$. The powders appear to lack the $\mathrm{O}-\mathrm{H}$ vibrational bands indicated by the weak peak at $630 \mathrm{~cm}^{-1}$ (Figure 8(a)) [38]. The sharp bands at $1024-1025 \mathrm{~cm}^{-1}$ correspond to $v 3$ asymmetric stretching modes of $\left(\mathrm{PO}_{4}\right)^{3-}$ groups. Moreover, the increase of the calcination temperature to $800^{\circ} \mathrm{C}$ caused the appearance of the peaks at 1500 and $3700-3500 \mathrm{~cm}^{-1}$. The addition, IR bands in the range of $3700-3500 \mathrm{~cm}^{-1}$ (Figure 8(b)) were also observed by Duta et al. [39], which was assigned them to the $\mathrm{O}-\mathrm{H}$ stretching vibrations of surface $\mathrm{P}-\mathrm{OH}$ groups. These spectra are in agreement with the XRD results.

\section{Conclusions}

Using a simple mechanochemical method, biphasic bioceramic nanopowders of hydroxyapatite (HA) and tricalcium phosphate (TCP) were fabricated. It has been indicated that 
these nanopowders can be used as bioceramic for graft material. The shell of a regular sea snail from the species Cerithium vulgatum was successfully transformed into the target compounds. This new method is very simple, economic, and safe.

\section{Conflict of Interests}

The authors declare that there is no conflict of interests regarding the publication of this article.

\section{Acknowledgments}

This study was carried out partly with the equipment furnished (between 2007 and 2008) to Marmara University with the support of the Turkish Republic Government Planning Organization in the framework of the Project 2003K120810 "Manufacturing and Characterization of Electro-Conductive Bioceramics." The authors also acknowledge the very valuable support of the Metallurgical and Materials Engineering Department, Istanbul Technical University, Turkey.

\section{References}

[1] D. Lahiri, S. Ghosh, and A. Agarwal, "Carbon nanotube reinforced hydroxyapatite composite for orthopedic application: a review," Materials Science and Engineering C, vol. 32, no. 7, pp. 1727-1758, 2012.

[2] M. R. Foroughi, S. Karbasi, and R. Ebrahimi-Kahrizsangi, "Physical and mechanical properties of a poly-3-hydroxybutyrate-coated nanocrystalline hydroxyapatite scaffold for bone tissue engineering," Journal of Porous Materials, vol. 19, no. 5, pp. 667-675, 2012.

[3] F. N. Oktar, M. R. Demirer, O. Gunduz et al., "Sintering effect on mechanical properties of composites of bovine hydroxyapatite (BHA) and $\mathrm{Li}_{2} \mathrm{O}$," Key Engineering Materials, vol. 309-311, pp. 49-52, 2006.

[4] S. J. Roll, Processing of hydroxyapatite by biomimetic process, a thesis submitted in partial fulfilment of the requirement for the degree of bachelor of technology [M.S. thesis], Department of Ceramic Engineering, National Institute of Technology Rourkela, Odisha, India, 2006-2010.

[5] G. Goller, F. N. Oktar, L. S. Ozyegin, E. S. Kayali, and E. Demirkesen, "Plasma-sprayed human bone-derived hydroxyapatite coatings: effective and reliable," Materials Letters, vol. 58, no. 21, pp. 2599-2604, 2004.

[6] L. S. Ozyegin, F. N. Oktar, G. Goller, E. S. Kayali, and T. Yazici, "Plasma-sprayed bovine hydroxyapatite coatings," Materials Letters, vol. 58, no. 21, pp. 2605-2609, 2004.

[7] N. Demirkol, F. N. Oktar, and E. S. Kayali, "Mechanical and microstructural properties of sheep hydroxyapatite (SHA)niobium oxide composites," Acta Physica Polonica A, vol. 121, no. 1, pp. 274-276, 2012.

[8] G. Goller and F. N. Oktar, "Sintering effects on mechanical properties of biologically derived dentine hydroxyapatite," Materials Letters, vol. 56, no. 3, pp. 142-147, 2002.

[9] F. N. Oktar, "Microstructure and mechanical properties of sintered enamel hydroxyapatite," Ceramics International, vol. 33, no. 7, pp. 1309-1314, 2007.
[10] N. Akyurt, U. Karacayli, M. Yetmez, S. S. Pazarlioglu, and F. N. Oktar, "Microstructure and mechanical properties of sintered sheep enamel-derived hydroxyapatite," International Journal of Artificial Organs, vol. 34, no. 8, p. 700, 2011.

[11] N. Demirkol, M. Yetmez, U. Karacayli et al., "Mechanical properties of hydroxyapatite-tantalum composites," International Journal of Artificial Organs, vol. 33, p. 468, 2010, (XXXVII Annual ESAO Congress) Skopje, R. Macedonia from 8th to 11th September 2010.

[12] K. Lewis, U. Boonyang, L. Evans, S. Siripaisarnpipat, and B. BenNissan, "A comparative study of Thai and Australian crocodile bone for use as a potential biomaterial," Key Engineering Materials, vol. 309-311, pp. 15-18, 2006.

[13] M. Bǎciuţ, G. Bǎciuţ, V. Simon et al., "Investigation of deer antler as a potential bone regenerating biomaterial," Journal of Optoelectronics and Advanced Materials, vol. 9, no. 8, pp. 25472550, 2007.

[14] J. H. G. Rocha, A. F. Lemos, S. Agathopoulos et al., "Scaffolds for bone restoration from cuttlefish," Bone, vol. 37, no. 6, pp. 850857, 2005.

[15] A. F. Lemos, J. H. G. Rocha, S. S. F. Quaresma et al., "Hydroxyapatite nano-powders produced hydrothermally from nacreous material," Journal of the European Ceramic Society, vol. 26, no. 16, pp. 3639-3646, 2006.

[16] B. B. Nissan, A. S. Milev, D. D. Green et al., "Processes for treating coral and coating an object," US patent no. 2004/0091547 A1, 2004

[17] D. Agaogulları, D. Kel, H. Gokce et al., "Bioceramic production from sea urchins," Acta Physica Polonica A, vol. 121, no. 1, pp. 23-26, 2012.

[18] R. Samur, L. S. Ozyegin, and D. Agaogullari, "Calcium phosphate formation from dea urchin-(brissus Latecarinatus) via modified mechano-chemical (ultrasonic) conversion method," Metalurgija, vol. 52, pp. 375-378, 2013.

[19] A. U. Tuyel, E. T. Oner, S. Ozyegin, and F. N. Oktar, "Production and characterization of bioceramic nanopowders of naturalbiological origin," Journal of Biotechnology, vol. 131S, p. S-65, 2007.

[20] M. L. Tamasan, L. S. Ozyegin, F. N. Oktar, and V. Simon, "Characterization of calcium phosphate powders originating from Phyllacanthus imperialis and Trochidae Infundibulum concavus marine shells," Materials Science and Engineering C, vol. 33, no. 5, pp. 2569-2577, 2013.

[21] D. Kel, H. Gökçe, D. Bilgiç et al., "Production of natural bioceramic from land snails," Key Engineering Materials, vol. 493-494, pp. 287-292, 2012.

[22] I. J. Macha, L. S. Ozyegin, J. Chou, R. Samur, F. N. Oktar, and B. Ben-Nissan, "An alternative synthesis method for di calcium phosphate (Monetite) powders from mediterranean mussel (Mytilus galloprovincialis) shells," Journal of the Australian Ceramic Society, vol. 49, pp. 122-128, 2013.

[23] S. Agathopoulos, L. S. Ozyegin, Z. Ahmad et al., "Nanobioceramics production from razor shell," Key Engineering Materials, vol. 493-494, pp. 775-780, 2012.

[24] F. N. Oktar, U. Tuyel, N. Demirkol et al., "A new safe method to produce bioceramic nano-powders from nacre venus verrucosa," International Journal of Artificial Organs, vol. 33, pp. 467-468, 2010, (XXXVII Annual ESAO Congress) Skopje, R. Macedonia from 8th to 11th September 2010.

[25] A. U. Tuyel, Production and characterization of bioceramic nanopowders of natural-biological origin [M.S. thesis], Institute 
for Graduate Studies in Pure and Applied Sciences, T.C. Marmara University, 2008.

[26] D. Kel, U. Karacayli, M. Yetmez, L. S. Ozyegin, E. S. Kayalı, and F. N. Oktar, "Hydroxyapatite production with various techniques from sea urchin," International Journal of Artificial Organs, vol. 34, p. 700, 2011.

[27] April 2013, http://www.marinespecies.org/aphia.php?p=taxdetails\&id=139066.

[28] April 2012, http://en.wikipedia.org/wiki/Cerithium_vulgatum.

[29] A. S. Ates, T. Katagan, and A. Kocataş, "Gastropod shell species occupied by hermit crabs (Anomura: Decapoda) along the Turkish coast of the Aegean Sea," Journal of Zoology, vol. 31, pp. 13-18, 2007.

[30] April 2013, http://www.idscaro.net/sci/01_coll/plates/gastro/ pl_cerithiidae_1.htm.

[31] April 2012, http://www.eu-nomen.eu/portal/taxon.php?GUID= urn:Isid:marinespecies.org:taxname:139066.

[32] V. I. Zdun and S. M. Ignat'ev, "Black Sea mollusc, Cerithium vulgatum (Gastropoda, Cerithiidae), a new intermediate trematode host," Parazitologiia, vol. 14, no. 4, pp. 345-348, 1980.

[33] L. S. Ozyegin, F. Sima, C. Ristoscu et al., "Sea snail: an alternative source for nano-bioceramic production," Key Engineering Materials, vol. 493-494, pp. 781-786, 2012.

[34] U. Balthasar and M. Cusack, "Aragonite-Calcite seas and evolution of biocalcification," in Proceedings of the 22nd V.M. Goldschmidt Conference, Earth in Evaluation, Montreal, Canada, 2012.

[35] J. J. Song, An in vitro investigation of the spatial control involved in collagen mineralization [M.S. thesis], University of Toronto, 2010.

[36] S. Sai and K. Fujii, "ß-tricalcium phosphate as a bone graft substitut," Jikeikai Medical Journal, vol. 52, pp. 47-54, 2005.

[37] P. Hernigou, X. Roussignol, C. H. Flouzat-Lachaniette, P. Filippini, I. Guissou, and A. Poignard, "Opening wedge tibial osteotomy for large varus deformity with Ceraver TM resorbable beta tricalcium phosphate wedges," International Orthopaedics, vol. 34, no. 2, pp. 191-199, 2010.

[38] A. R. Boyd, B. J. Meenan, and N. S. Leyland, "Surface characterisation of the evolving nature of radio frequency (RF) magnetron sputter deposited calcium phosphate thin films after exposure to physiological solution," Surface and Coatings Technology, vol. 200, no. 20-21, pp. 6002-6013, 2006.

[39] L. Duta, F. N. Oktar, G. E. Stan et al., "Novel doped hydroxyapatite thin films obtained by pulsed laser deposition," Applied Surface Science, vol. 265, pp. 41-49, 2013. 

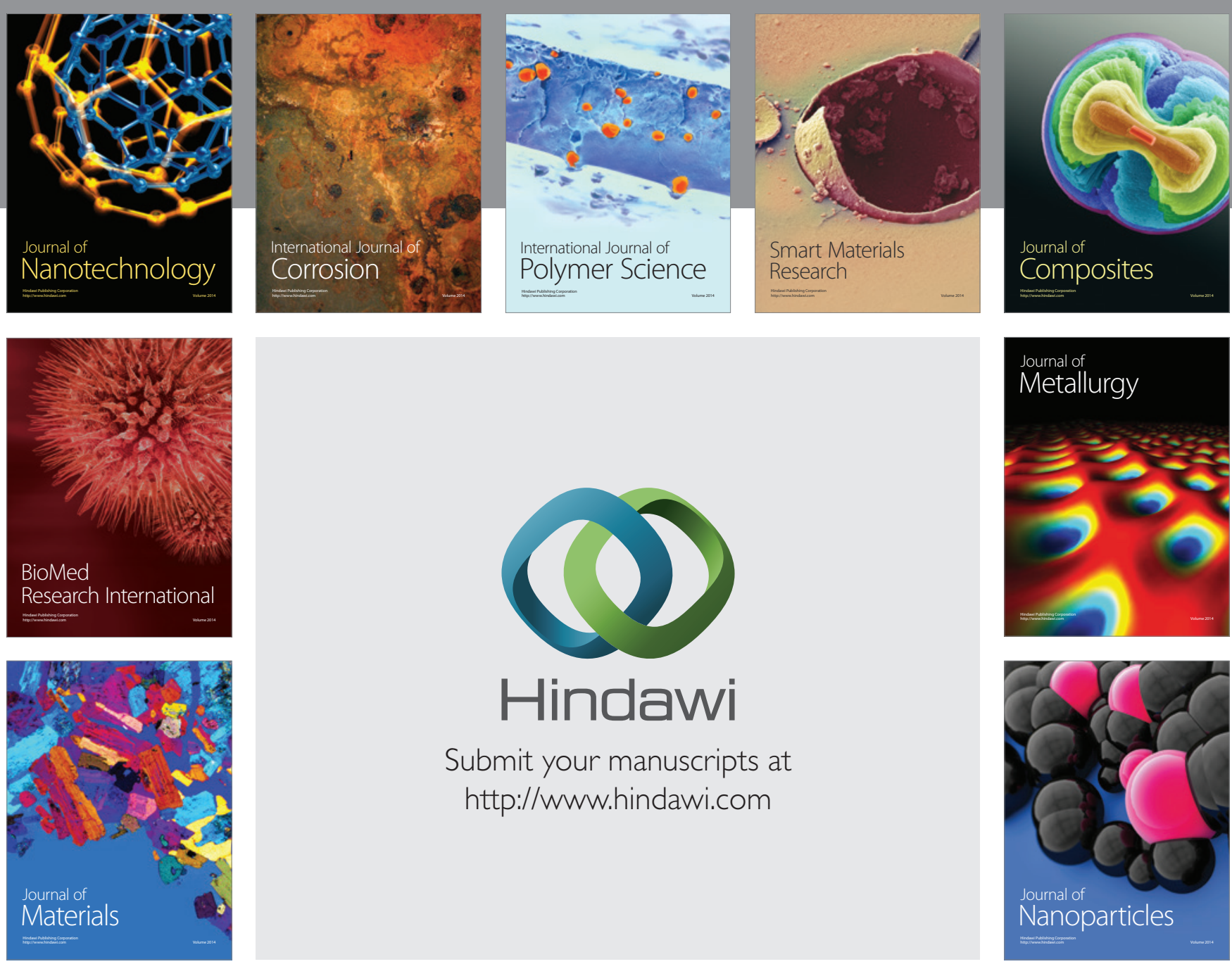

Submit your manuscripts at http://www.hindawi.com
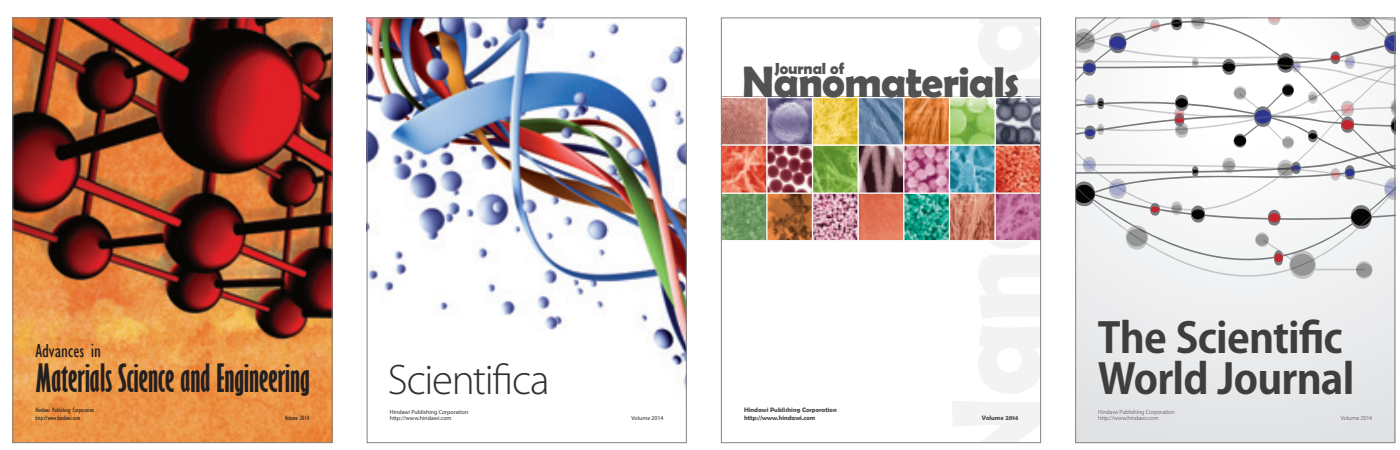

\section{The Scientific World Journal}
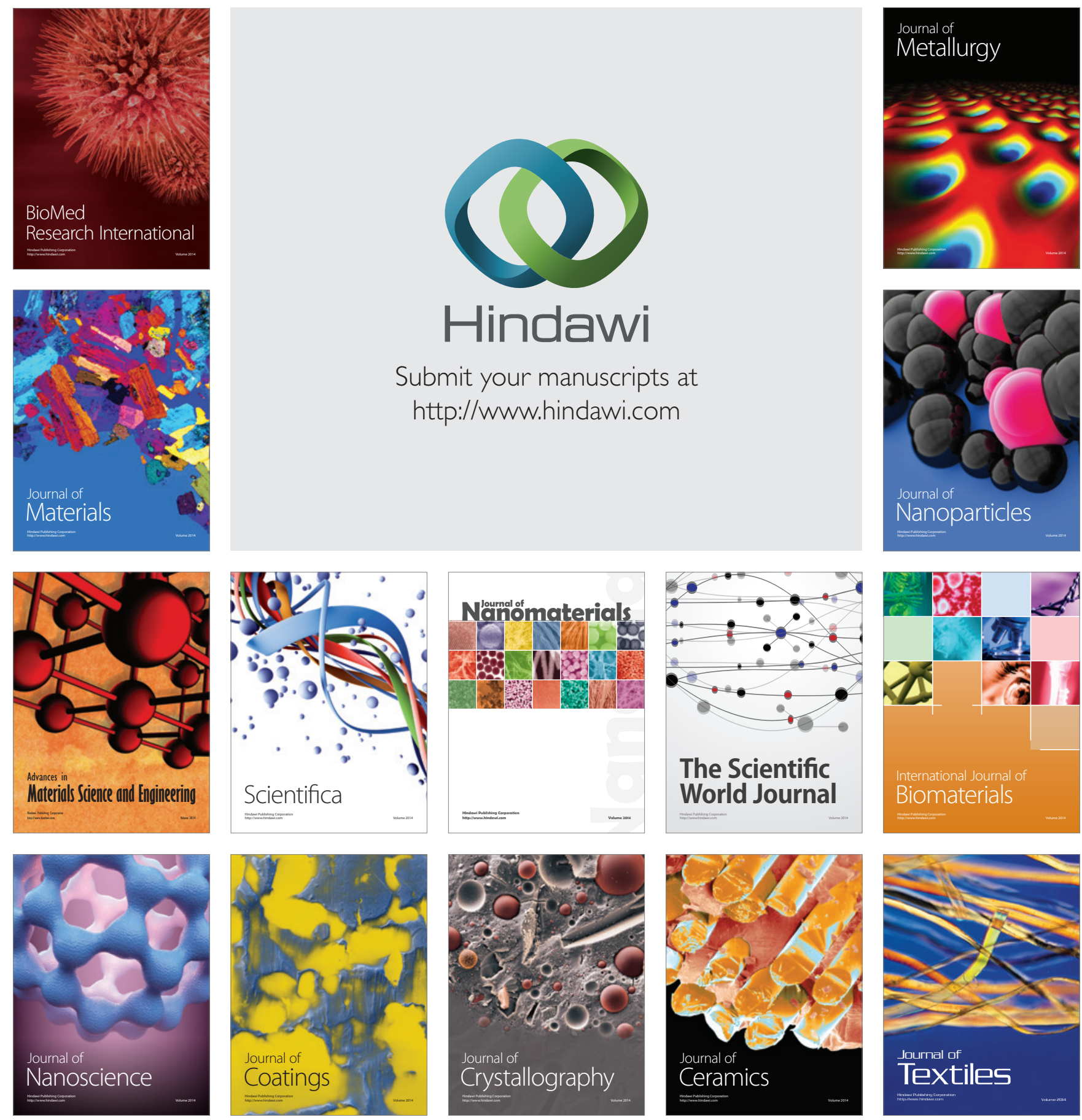